\title{
Assessing the Effectiveness of Mobile Learning Devices in Tertiary Institutions: The Experience of Undergraduates in a Nigerian Private University
}

\author{
https://doi.org/10.3991/ijim.v11i4.6828 \\ Jonathan A. Odukoya, \\ Covenant University, Ota, Nigeria \\ adedayo.odukoya@covenantuniversity.edu.ng \\ Olujide Adekeye \\ Covenant University, Ota, Nigeria \\ jide.adekeye@covenantuniversity.edu.ng \\ Olusola Okunlola \\ Covenant University, Ota, Nigeria \\ solami.okunlola@gmail.com
}

\begin{abstract}
Over the years, technology appears to be making life easier and better. However, in some instances, it appears technology is counterproductive. Mobile learning devices, as the name suggests, have been developed to facilitate learning on the move. The questions are: Are these devices truly facilitating learning? If they are truly facilitating learning, are they facilitating learning positively or negatively? To answer these questions, the survey research design was adopted on a sample of 215 randomly selected students. In the process, questionnaire and focused group discussion guideline were used to collect relevant data. Data analysis was both qualitative and quantitative. Some of the core findings from this investigation were that majority of the respondents, and by extension the target population, were barely using the tablets and free internet browsing megabytes [10 Gb monthly] given to all students for the intended purpose of learning. Some were pre-occupied with downloading videos, films and music while some spend endless hours playing computer games or chatting on social networks with the attendant consequence of poor learning, dwindling academic performance and productivity. Relevant recommendations to redress this unwholesome trend were proffered.
\end{abstract}

Keywords-Assessment, Mobile Learning Devices, Tertiary Institutions, Undergraduates, University, Learning

\section{Introduction}

The advent of technology has been transforming virtually all spheres of life, including the education sector. With computer and information technology [ICT] 
there is literal information explosion. The challenging fallout of this development, however, is that it appears there are some negative, almost debilitating effect of ICT, and especially the Mobile Learning Devices [MLD] like tablets.

A student of mine recently reported that she engaged in online chatting for virtually ten hours on a Saturday while on campus. At times, the chat extended into the night. According to her, she just couldn't stop it. Further probing questions revealed that the online chat got extended predominantly because of the sexual undertone. The worst part of the experience was that she literally neglected all her pending academic assignments and personal studies in the process. One of her Lecturers popped up a Continuous Assessment test the following day and she performed poorly. Despite this result, the following day, my internet-addicted student still engaged in another round of extended online chat and browsing, which lasted almost four hours. An extrapolation of this scenario to the millions of youth, supposed leaders of tomorrow, spread all over the nations, and the concomitant long-term effect on national development is better imagined than experienced. It is a situation that calls for urgent attention, hence this study.

Akers et. al [1] reported the short-term results from a randomized evaluation of a mobile phone literacy and numeracy program (Project ABC) in Niger, in which adult literacy students learned how to use mobile phones as part of a literacy and numeracy class. Students in ABC villages showed substantial gains in numeracy exam scores. There is also evidence of heterogeneity in program effects across regions, suggesting the impact is context dependent. The results were stronger in one region, for women and for participants younger than 45 . There was also evidence of persistent impacts: six months after the end of the first year of classes, students in $\mathrm{ABC}$ villages retained what they had learned better than the non-ABC students. The effects do not appear to be driven by differences in teacher quality and motivation, nor student attendance.

Several previous researches highlighted the effect of educational technology on student achievements. The majority of the researchers illustrated that technology has a positive impact on student achievements or that technology has no impact on student achievements. Only very few studies illustrated that technology has a negative impact on student achievements [3]. This study attempted to fill this lacuna.

Valk et. al. [2] examined the extent to which the use of mobile phones helped to improve educational outcomes in two specific ways: 1) in improving access to education, and 2) in promoting new learning. They reviewed the evidence of the role of mobile phone-facilitated $\mathrm{m}$-Learning in contributing to improved educational outcomes in the developing countries of Asia by exploring the results of six m-Learning pilot projects that took place in the Philippines, Mongolia, Thailand, India, and Bangladesh. They concluded that the analysis of these projects indicates that while there is important evidence in the developing world that mobile phones impact educational outcomes by facilitating increased access, much less evidence exists as to how mobiles impact educational outcomes by promoting new learning.

The core research questions addressed in this study are: Which Website is Most Visited by Students?; Are the Mobile Learning Devices /MLD] facilitating learning? Are MLDs significant predictors of academic learning?; Are the Mobile Learning Devices facilitating learning positively or negatively?; In what ways were students 
using the 10Gb data provided by school authorities?; Are students' usage of the mobile learning device for academic purposes affected by gender factor?; and Are students' usage of the mobile learning devices for academic purposes affected by level of maturity [in terms of age]?

\section{$2 \quad$ Method}

The survey research design was adopted for this study since the focus was to harvest the experience and opinion of mobile learning device users. The population of study were undergraduate students of a Nigerian private university based in Ogun state. The population of study was estimated to be 8000 students. All the students were using mobile learning devices given by the university, specifically tablets. Out of this population, a sample of two hundred and fifteen [215] was selected via stratified sampling technique. spreading over 100 and 300. Table 1 below shows the distribution of the sample for 100 level students:

Table 1.

\begin{tabular}{|l|c|l|c|}
\hline \multicolumn{1}{|c|}{ College } & Frequency & \multicolumn{1}{c|}{ Gender } & Frequency \\
\hline CST & 70 & Male & 145 \\
\hline CLDS & 2 & & 70 \\
\hline CBSS & 19 & Female & $\mathbf{2 1 5}$ \\
\hline ENGR & 124 & Total & \\
\hline Total & $\mathbf{2 1 5}$ &
\end{tabular}

Source: Field Data [Odukoya et al, 2016]. CST = College of Science and Technology; CLDS = College of Leadership Development Studies; CBSS = College of Business and Social Sciences; ENGR = College of Engineering

Table 2. 300 Level Students involved in Focused Group Discussion

\begin{tabular}{|l|c|c|}
\hline Gender & Frequency & Percent \\
\hline Male & 11 & 40.7 \\
\hline female & 16 & 59.3 \\
\hline Total & 27 & 100.0 \\
\hline
\end{tabular}

Source: Field Data [Odukoya et al, 2016]

The instruments used for data collection in this study were: Questionnaire and Focused Discussion Guideline. The content validity of instruments was confirmed via experts' judgment.

After obtaining the consent of the Lecturer handling a university wide course, trained Research Assistants assisted in random administration of the questionnaire to 250 of the students. Thereafter, the Principal Researcher introduced the objective of the survey, drawing their attention to the fact that since their names were not required 
on the questionnaire, they should endeavor to give candid responses to the prompts, particularly regarding the CGPA. Out of the questionnaires administered, 215 were duly completed.

Descriptive statistics of frequency count and percentages were employed to furnish answers to the research questions. Pearson product-moment correlation coefficient and regression analyses were also computed to test the hypotheses raised for the study.

\section{$3 \quad$ Results \& Discussion}

\subsection{Which Website is Most Visited by Students?}

Table 3. Most Visited Websites

\begin{tabular}{|c|l|c|c|}
\hline S/N & $\mathbf{1 0}$ Most Visited Websites [Daily \& Every Other Day] & $\mathbf{N ~ [ 2 1 4 ]}$ & $\mathbf{\%}$ \\
\hline 1 & Google & 188 & $87.9 \%$ \\
\hline 2 & Instagram & 143 & $66.8 \%$ \\
\hline 3 & BBM & 133 & $62.1 \%$ \\
\hline 4 & Facebook & 127 & $59.3 \%$ \\
\hline 5 & Youtube & 125 & $58.4 \%$ \\
\hline 6 & Wikipedia & 113 & $52.8 \%$ \\
\hline 7 & Whatsapp & 82 & $38.3 \%$ \\
\hline 8 & Snapchat & 80 & $37.4 \%$ \\
\hline 9 & Twitter & 70 & $32.7 \%$ \\
\hline 10 & Skype & 49 & $22.9 \%$ \\
\hline
\end{tabular}

Source: Field Data (Odukoya et al, 2016)

Table 3 indicates that the website that is most visited by undergraduate students from the Nigerian private university studied is Google $(88.9 \%)$, followed by Instagram $(66.8 \%)$ and BBM (62.1\%).

It is important to note that out of the ten most visited websites, seven [7] of them were predominantly devoted to social networking [Instagram, BBM, Facebook, Whatsapp, Snapchat, Twitter, and Skype]. Google and Wikipedia could be classified as educational while Youtube could go for both educational and entertainment. It appears then that the sampled students were concurrently using their mobile learning devices for 'business' (learning business) and 'pleasure' (social networking). Cumulatively, however, it appears the 'pleasure' usage was more predominant.

\subsection{Are the Mobile Learning Devices /MLD] facilitating learning? Are MLDs significant predictors of academic learning?}

Tables 4 and 5 outputs show that Use of Mobile Learning Devices is not a significant predictor of students' academic performance. 
Results from Table 6 indicates that majority of the students $(65.9 \%)$ reported they experienced high academic impact in usage of mobile learning devices. However, this self-report tends not to agree with the result of the statistical test of hypotheses on this issue as presented in Tables 4 and 5.

Table 4. Model Summary

\begin{tabular}{|c|c|c|c|c|}
\hline Model & R & R Square & Adjusted R Square & Std. Error of the Estimate \\
\hline 1 & $.030^{\mathrm{a}}$ & .001 & -.010 & .601 \\
\hline
\end{tabular}

a. Predictors: (Constant), Frequency of MLD Usage

Table 5. Regression Output

\begin{tabular}{|c|l|c|c|c|c|c|}
\hline \multicolumn{2}{|c|}{ Model } & Sum of Squares & df & Mean Square & F & Sig. \\
\hline \multirow{3}{*}{1} & Regression & .029 & 1 & .029 & .080 & $.778^{\mathrm{b}}$ \\
\cline { 2 - 8 } & Residual & 32.195 & 89 & .362 & & \\
\cline { 2 - 8 } & Total & 32.224 & 90 & & & \\
\hline
\end{tabular}

a. Dependent Variable: CGPA - b. Predictors: (Constant), Frequency of MLD Usage

Table 6. Academic Impact Category

\begin{tabular}{|l|l|c|c|c|c|}
\hline \multicolumn{2}{|c|}{} & Frequency & Percent & Valid Percent & Cumulative Percent \\
\hline \multirow{3}{*}{ Valid } & $\begin{array}{l}\text { Lower Academic } \\
\text { Impact }\end{array}$ & 10 & 4.5 & 6.5 & 6.5 \\
\cline { 2 - 6 } & $\begin{array}{l}\text { Higher Academic } \\
\text { Impact }\end{array}$ & 145 & 65.9 & 93.5 & 100.0 \\
\cline { 2 - 6 } & Total & 155 & 70.5 & 100.0 & \\
\hline Missing & System & 65 & 29.5 & & \\
\hline \multicolumn{1}{|l|}{ Total } & 220 & 100.0 & & \\
\hline
\end{tabular}

\subsection{Are the Mobile Learning Devices facilitating learning positively or negatively?}

Table 7. I Go into unwholesome behaviour via internet interaction

\begin{tabular}{|l|l|c|c|c|c|}
\hline \multicolumn{2}{|c|}{} & Frequency & Percent & Valid Percent & Cumulative Percent \\
\hline \multirow{4}{*}{ Valid } & NEVER & 177 & 80.5 & 85.1 & 85.1 \\
\cline { 2 - 6 } & RARELY & 28 & 12.7 & 13.5 & 98.6 \\
\cline { 2 - 6 } & SOMETIMES & 3 & 1.4 & 1.4 & 100.0 \\
\cline { 2 - 6 } & Total & 208 & 94.5 & 100.0 & \\
\hline \multirow{2}{*}{ Missing } & System & 12 & 5.5 & & \\
\hline \multicolumn{2}{|l|}{ Total } & 220 & 100.0 & & \\
\hline
\end{tabular}

Table 7 indicates that $80.5 \%$ of the respondents reported they had never gone into unwholesome behavior due to negative influence via internet interaction on mobile devices. However, it is also noteworthy that $12.7 \%$ and $1.4 \%$ of the respondents reported they were rarely and sometimes negatively influenced respectively. 
Table 8. I encourage others into bad behaviour via internet interaction

\begin{tabular}{|l|l|c|c|c|c|}
\hline \multicolumn{2}{|c|}{} & Frequency & Percent & Valid Percent & Cumulative Percent \\
\hline \multirow{3}{*}{ Valid } & NEVER & 204 & 92.7 & 96.2 & 96.2 \\
\cline { 2 - 6 } & RARELY & 8 & 3.6 & 3.8 & 100.0 \\
\cline { 2 - 6 } & Total & 212 & 96.4 & 100.0 & \\
\hline Missing & System & 8 & 3.6 & & \\
\hline \multicolumn{2}{|l}{ Total } & 220 & 100.0 & & \\
\hline
\end{tabular}

Table 8 shows that $92.7 \%$ of the respondents reported they had never encouraged people into bad behaviours via internet interactions on mobile devices. This suggests that majority of the undergraduates in the Nigerian Private University studied did not use the mobile learning device given negatively.

\subsection{In what ways were students using the $10 \mathrm{~Gb}$ data provided by school authorities?}

Table 9. Popular Ways Students Were Using the Monthly 10GB

\begin{tabular}{|c|l|c|c|c|c|}
\hline S/N & \multicolumn{1}{|c|}{ Avenues of Usage } & $\mathbf{1 - 5} \mathbf{h r s} / \mathbf{d a y}[\mathbf{N}]$ & $\mathbf{\%}$ & $\mathbf{> 5}$ hrs/day [N] & $\mathbf{\%}$ \\
\hline 1 & Downloading Academic Information & 90 & 41.8 & 36 & 16.7 \\
\hline 2 & Downloading e-Books & 81 & 37.7 & 32 & 14.9 \\
\hline 3 & $\begin{array}{l}\text { Downloading and Watching Vide- } \\
\text { os/Films }\end{array}$ & 70 & 32.6 & 23 & 10.7 \\
\hline 4 & Music & 62 & 28.8 & 38 & 17.7 \\
\hline 5 & Chatting & 60 & 27.9 & 33 & 15.3 \\
\hline 6 & Games & 41 & 19.1 & 14 & 6.5 \\
\hline
\end{tabular}

Source: Field Data (Odukoya et al, 2016)

Table 9 indicates that majority of the students used their monthly10GB browsing unit for academic purposes [Downloading academic information (41.8\%) and Downloading e-books (37.7\%)], a significant percentage of the respondents used the mobile devices for non-academic purposes [watching videos and films (32.6\%); Music (28.8\%); Chatting (27.9\%) and playing games (14.1\%)]

3.5 Are students' usage of the mobile learning device for academic purposes affected by gender factor?

Table 10.

\begin{tabular}{|l|l|c|c|c|c|c|}
\hline & Gender & Mean & N & df & t & Sig [p] \\
\hline \multirow{2}{*}{ AcademicImpactofMobTab } & Male & 6.5357 & 112 & \multirow{2}{*}{154} & \multirow{2}{*}{-1.412} & \multirow{2}{*}{.161} \\
\cline { 2 - 5 } & Female & 6.9091 & 44 & & \\
\hline
\end{tabular}

Equal variance not assumed

From Table 10, gender factor tend not to have significant impact on effect of mobile learning devices on academic performance. 
3.6 Are students' usage of the mobile learning devices for academic purposes affected by level of maturity [in terms of age]?

Table 11.

\begin{tabular}{|l|c|c|c|c|c|c|}
\hline & AGE & Mean & N & df & t & Sig [p] \\
\hline \multirow{2}{*}{ AcademicImpactofMobTab } & $17-18$ & 6.5294 & 85 & \multirow{2}{*}{142} & -.108 & \multirow{2}{*}{0.915} \\
\cline { 2 - 7 } & $15-16$ & 6.5593 & 59 & & & \\
\hline
\end{tabular}

Table 11 shows that level of maturity, as depicted by respondents' age, does not have significant impact on the effect of mobile learning devices on academic performance.

\subsection{Which of the websites are most preferred by students?}

Table 12. Six (6) Most Preferred Websites

\begin{tabular}{|c|l|c|c|}
\hline S/N & Website $[\mathbf{N}=\mathbf{2 2 0}]$ & Frequency & \% \\
\hline 1 & Instagram & 27 & 12.3 \\
\hline 2 & Facebook & 27 & 12.3 \\
\hline 3 & Google & 26 & 11.8 \\
\hline 4 & BBM & 22 & 10 \\
\hline 5 & Twitter & 9 & 4.1 \\
\hline 6 & Whatsapp & 9 & 4.1 \\
\hline
\end{tabular}

Out of the six (6) most preferred websites indicated by respondents, only one (Google $-11.8 \%$ ) tend to be inclined toward enhancing learning. The remaining five are virtually social network websites

Though the overriding finding from this study is that majority of students tend to use the mobile devices and the chunk of their browsing time and gigabyte for social working and related non academic purposes, yet majority of the respondents tend to assert that the Mobile devices enhance their academic performance. Furthermore, the statistical test of the null hypothesis on the effect of mobile devices at enhancing academic learning was accepted. The result obtained might have been limited by the mode of obtaining the Cumulative Grade Point Average [CGPA] directly from the respondents. The protocol for obtaining the students' CGPA was almost impossible, hence the resort to this method. Further study is therefore recommended that could make use of the actual students' CGPA or a fresh assessment of general knowledge.

The Focused Group Discussion and Interview further affirmed that undergraduate students often get distracted with using their mobile devices for social networking more than academic purposes. 
3.8 Focused Group Discussion with 300 Level Psychology Students on Use of Mobile Learning Devices [MLD] in Higher Institutions - Transcript Extract

Intro: Recently the University gave all students mobile learning tabs. This discussion is to get the efficacy of the devices. Are they really facilitating learning?

Researcher Prompt: Are the MLDs facilitating learning positively or negatively?

Student Response 1: The tabs are very effective in my opinion cos they give us easier access to a lot of soft ware like usually to download some MS office, you need a lot of time and data, but with the tab, we have a lot of data, we have apolaris already, we have file manager, everything is organized, we have easy access to the internet, it makes everything kind of mobile, easy to carry around and access information, hence in that wise, it facilitates learning.

Student Response 2: The MLD, which is the tabs, they are very effective in my own opinion, that is in terms of facilitating learning. I will give an example of last week in class, I had a note and others in class did not have it and I needed to give them, so I just said put on your wifi direct and they were able to get the notes in few minutes, so in terms of transferring knowledge or information, it is very useful, effective.

Student Response 3: Looking at it with the way it has affected leaning positively, for some people that do not have laptops who have to always go to library to use the system or have to wait for their friends to use their laptops, I think school giving everybody a tab, made the chances of everybody learning kind of more equal than what it was before. Like for me, my laptop is not really good and if I don't have this tab, I will not be a able to read well for the EDS course I just finished now, because I have my notes on it. Apart from reading, it also helps me to plan my day; plan my time. I can easily just do a list of things I need to do and check what and what I have done easily, through my tab.

Researcher's Prompt: What are the Negative Impacts of the MLD?

Student Response 4: For example in class, when you are trying to teach and someone is in class, connected to wifi, doing other extra-curricular activities; snapchatting, tweeting, bbm etc. things like that are very possible, almost frequently and it is a major distraction.

Student Response 6: The tab is not SIM enabled, so there is limited connection to the internet, if you are in an environment without internet, your resources are limited. you can't use even the moodle. You try multiple times to connect $2 \mathrm{G}$ that is enabled on the tab, you can't even connect at times. Poor internet connection and the camera is not good even to snap somebody's note, you cannot. Thus limiting learning abilities

Student Response 7: Any other angle? Some of us are old schools. You know the various ways to use the internet for instance what are the popular various social platform we normally go to? Twitter, bbm, facebook, whatsapp. The question is what are the negative sides to using internet? For example, apart from chatting, some people go to the internet to watch pornography, internet sex and that is what prolong those chats because when they are telling you the sweet nonsense you are enjoying it one hour and so on. 
Researcher's Prompt: Let another person contribute please

Student Response 8: Another disadvantage is that times when you want to read at night is when the Wi-Fi gets most wonderful and people gets tempted to and they just switch from reading to browsing.

Researcher's Prompt: Is it a distracting instrument? Can all students really control themselves to be able to use it for academic purposes? From the questionnaire, it reveals that some students kept complaining the 10GB is not enough for them. What are they using it for?

Student Response 9: For some people, the 10Gig is not enough for them like some of my friends in engineering who do drawings. Some people actually spend their $10 \mathrm{~GB}$ on academic stuff though not everybody. It's not that they can't do a tab without social stuff. But once you are connected to the internet, you can always be distracted.

These findings tend to be in consonance with Waker's [3] submission that only very few studies illustrated that technology has a negative impact on student achievements.

\section{Recommendation \& Conclusion}

There is no doubt that ICT mobile devices hold a lot of promise in enhancing effective teaching and learning. However, the need to apply oneself to self-discipline is germane to deriving the full benefit of the devices. Mobile learning devices are like two-edged swords. They hold promise of registering positive or negative learning experiences. Surfing the web is like surfing an ocean of information. There are 'sharks' out there. It takes sensitivity, skill and self-control to maximize their potentials. More concerted training and sensitization are apparently needed to help the teeming undergraduates in Nigeria and the larger world to make the best of the ICT mobile devices at enhancing positive learning experiences in the midst of the multifarious web traps and distractions. Some of the controls could also be programmed and wittingly applied by university managements.

\section{$5 \quad$ References}

[1] Akers, J. C., Ksoll, C., and Lybbert, T. (2010). ABC, 123: Can you Text me Now? The Impact of a Mobile Phone Literacy Program on Educational Outcomes.

[2] Valk, J-H., Rashid, A. T., and Elder, L. (2010). Using Mobile Phones to Improve Educational Outcomes - An Analysis of Evidence from Asia. Pan Asia Networking, IDRC, Canada

[3] Waker, M.L. (2001). The Predictors of Student Achievement in Computer Integrated Learning Environments. Doctoral dissertation, Wayne State University.

\section{Acknowledgement}

We hereby acknowledge the invaluable support and sponsorship rendered by the Management of Covenant University, Ota, Nigeria towards this publication. 


\section{$7 \quad$ Authors}

Dr. Jonathan Adedayo Odukoya is a Senior Lecturer in the Department of Psychology, Covenant University, Ota, Ogun State, Nigeria. He obtained his doctoral degree in Psychometrics from the Department of Guidance and Counseling, University of Ibadan in 1991. He lectured briefly as Lecturer I in the Department of Psychology, Obafemi Awolowo University, Ile-Ife before joining the Research Division of the West African Examinations Council [WAEC] in Lagos and subsequently in Accra, Ghana where he served for eleven years. The exposure afforded him the opportunity to serve as Consultant to international organizations like UNICEF, UNESCO, ADEA, IDRC, ERNWACA and USAID/AED, among others. He is a specialist in the development, standardization and administration of Psychological \& Educational tests cum evaluation of measurement outcomes. Dr. Odukoya, currently the Director of Covenant University Centre for Lifelong Learning. He is also the Secretary General of the Educational Research Network for West and Central Africa [ERNWACA] in Nigeria. Dr. Odukoya is a member of the American Psychological Association [APA]

Dr. O. A. Adekeye is a Associate Professor in the Department of Psychology, Covenant University, Ota, Ogun State, Nigeria. He received his $\mathrm{PhD}$. in Counselling Psychology from the Department of Psychology, Covenant University in 2009. He is a professional counsellor and lectures in the Department of Psychology. He is also involved in the partnership of Covenant University with the Prison Fellowship of Nigeria and SMEDAN tagged the "Onesimus Project" where psychosocial, therapeutic and rehabilitation training is rendered to prison inmates. His research interest revolves around young people in areas traversing academic performace, career studies, family and relationship counselling, HIV/AIDS education, adolescent development and substance abuse. He was the former Coordinator of International Students in Covenant University's International Office and Linkages. Dr. Adekeye is well travelled and has contributed to knowledge by publishing widely in local and international academic journals. He is an active member of the Counselling Association of Nigeria (CASSON) and a member of the Special Interest Group, Task Force on Indigenous Psychology, Division 32 (Society for Humanistic Psychology) of the American Psychological Association (APA). He is also an alumnus of the Brown International Advanced Research Institute, Brown University, Providence, R.I., USA. He is a Reviewer of many reputable professional journals outside Nigeria.

Olusola Okunlola is a doctoral student in the department of Psychology, Covenant University, Ota, Ogun State, Nigeria. She has 12 years experience in teaching, training and development had Masters in educational psychology from University of Lagos and a Master of Divinity degree in religious education from the Nigerian Baptist Theological Seminary Ogbomoso. Olusola holds a B.Sc. (Ed) in Chemistry Education from the University of Ilorin. She is a certified management trainer from the Centre for Management Development (CMD), Shangisha, Lagos, Nigeria. She is an alumnus of the famous Daystar Leadership Academy and Haggai Institute. Her research interests, comprises adolescents' educational, socio-emotional and religious aspects.

Article submitted 02 March 2017. Published as resubmitted by the authors 14 April 2017. 